NASA-TM-106,201

NASA Technical Memorandum 106201

AIAA-93-1968

19930019063

\title{
Mixing and Transient Interface Condensation of a Liquid Hydrogen Tank
}

C.S. Lin

Analex Corporation

Brook Park, Ohio

and

M.M. Hasan and T.W. Nyland

Lewis Research Center

Cleveland, Ohio

Prepared for the

29th Joint Propulsion Conference and Exhibit cosponsored by the AIAA, SAE, ASME, and ASEE

Monterey, California, June 28-30, 1993

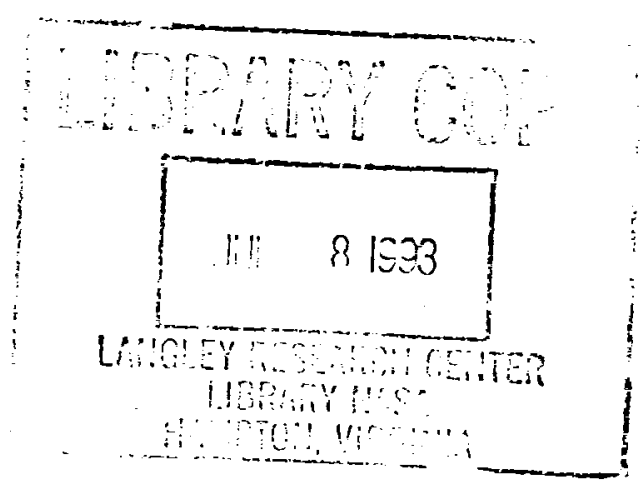




\title{
MIXING AND TRANSIENT INTERFACE CONDENSATION OF A LIQUID HYDROGEN TANK
}

\author{
C.S. Lin \\ Analex Corporation \\ 3001 Aerospace Parkway \\ Brook Park, Ohio 44142 \\ M.M. Hasan and T.W. Nyland \\ National Aeronautics and Space Administration \\ Lewis Research Center \\ Cleveland, Ohio 44135
}

\begin{abstract}
Experiments have been conducted to investigate the effect of axial jet-induced mixing on the pressure reduction of a thermally stratified liquid hydrogen tank. The tank was nearly cylindrical, having a volume of about $0.144 \mathrm{~m}^{3}$ with $0.559 \mathrm{~m}$ in diameter and $0.711 \mathrm{~m}$ long. A mixer/pump unit, which had a jet nozzle outlet of $0.0221 \mathrm{~m}$ in diameter was located $0.178 \mathrm{~m}$ from the tank bottom and was installed inside the tank to generate the axial jet mixing and tank fluid circulation. The liquid fill and jet flow rate ranged from $\mathbf{4 2}$ to 85 percent (by volume) and 0.409 to $2.43 \mathrm{~m}^{3} / \mathrm{hr}$, respectively. Mixing tests began with the tank pressure ranging from 187.5 to $238.5 \mathrm{kPa}$ at which the thermal stratification results in 4.9 to $6.2 \mathrm{~K}$ liquid subcooling. The mixing time and transient vapor condensation rate at the liquid-vapor interface are determined. Two mixing time correlations, based on the thermal equilibrium and pressure equilibrium, are developed. Both mixing time correlations are expressed as functions of system and buoyancy parameters and compared well with other experimental data. The steady state condensation rate correlation of Sonin et al. based on steam-water date is modified and expressed as a function of jet subcooling. The limited liquid hydrogen data of the present study shows that the modified steady state condensation rate correlation may be used to predict the transient condensation rate in a mxing process if the instantaneous values of the jet subcooling and the turbulence intensity at the interface are employed.
\end{abstract}

\section{Nomenclature}

A.

$C_{p}$

D

d

g

H liquid height from the tank bottom

$\mathrm{H}_{\mathrm{j}}$ jet submergence depth or the distance between nozzle outlet and liquid surface h

$\mathrm{h}_{\mathrm{fg}}$

Ja

L

$\mathbf{m}_{\mathrm{c}}$

$P$

Pr

$Q_{j}$

$\mathrm{Ri}$

$\mathbf{R e}_{\mathbf{j}}$

$\mathrm{St}_{\mathrm{c}}$

$T_{b}, T_{j}$

$T_{a}, T_{\text {dome }}$

$\left(\mathrm{T}_{\mathrm{s}}-\mathrm{T}_{\mathrm{j}}\right)_{\mathrm{i}}$

$t_{m}, t_{m}^{*}$

$\left(t_{m}\right)_{t h},\left(t_{m}\right)_{p}$

$\mathbf{u}_{\mathbf{j}}$

$v_{1}$

$\mathbf{v}_{\mathrm{B}}$

Greek Symbols

$\beta$

$\beta_{1}, \beta_{2}$

$\nu$

$\rho$ height measured from the tank bottom

latent heat of condensation

liquid Jakob number, $C_{p}\left(T_{s}-T_{b}\right) / h_{f g}$

tank height

average mass condensation rate at the liquid-vapor interface

tank pressusre

Prandtl number of bulk liquid

jet volume flow rate

Richardson number evaluated at the beginning of each test, $g \beta\left(T_{s}-T_{j}\right)_{i} H_{j} / u_{j}{ }^{2}$

jet Reynolds number, $u_{j} d / \nu$

average condensation Stanton number defined in Eq. (8)

bulk liquid temperature, jet temperature, interace temperature, and dome temperature

initial jet subcooling of each test

mixing time, dimensionless mixing time

mixing time based on the thermal and pressure equilibrium, respectively

jet velocity

liquid volume

average rms turbulent velocity (or turbulence intensity) at the liquid-vapor interface

$\beta \quad$ thermal expansion of liquid

constants defined in Eq. (10)

kinetic viscosity of liquid

liquid density 


\section{Introduction}

Fluid mixing such as axial jet-induced mixing is a preferred method to reduce the tank pressure of a twophase system in a closed container in which the fluid is thermally stratified. ${ }^{1}$ A typical example is the thermal destratification and the pressure reduction of a cryogenic storage tank by axial jet-induced mixing. As the tank is subjected to external heating, the fluid is thermally stratified and the tank pressure increases with a rate usually higher than its homogeneous pressure rise rate. By using a mixer, the tank fluid is circulated and the subcooled jet can be directed towards the liquid-vapor interface. The mixing of the tank fluid induced by the jet can destroy the temperature stratification and induce the vapor condensation at the interface, resulting in the reduction of tank pressure. Once the liquid temperature stratification is eliminated, the bulk liquid temperature is nearly saturated. Consequently, the continuation of mixing will not further reduce the tank pressure. Instead, the mixer power input, which may be significant for a cryogenic storage system, will eventually become heat and increase the boiloff losses. Therefore, the mixing process, which involves the mixing time and the vapor condensation rate at the interface, needs to be well understood such that the pressure control system can be properly designed and operated.

Fluid mixing process has been extensively investigated and numerous correlations to predict the mixing time have been proposed. However, the concept to formulate the mixing time data differ from one to another. Most of the tests were conducted with cylindrical tanks using water as the test fluid with a uniform temperature and injected dye of equal density to eliminate the buoyancy force. Some of the previous studies on mixing time are as follows:

Fossett and Prosser ${ }^{1}$

$$
t_{m}=8 \frac{D^{2}}{\left(Q_{j} u_{j}\right)^{1 / 2}}\left(=9 \frac{D^{2}}{u_{j} d}\right) \text { for } \quad R e_{j}>4500
$$

Fox and $\mathrm{Gex}^{2}$

$$
t_{m}=118 \frac{H^{1 / 2} D}{\operatorname{Re}_{j}^{1 / 6}} \frac{1}{\left(u_{j} d\right)^{4 / 6}} \frac{1}{g^{1 / 6}} \text { for } \operatorname{Re}_{j}>2000
$$

Okita and Oyama ${ }^{3}$

$$
t_{m}=5.5\left(\frac{D^{2}}{u_{j} d}\right)\left(\frac{H}{D}\right)^{0.5} \quad \text { for } \quad R e_{j}>5000
$$

Wollen ${ }^{4}$

$$
t_{m}=9.46 \frac{D^{2}}{u_{j} d}
$$

For comparison purpose, Okita and Oyama ${ }^{3}$ recalculated the data of Fox and Gex ${ }^{2}$ and obtained the following correlation which is independent of jet Reynolds number:

$$
t_{m}=2.6\left(\frac{D^{2}}{u_{j} d}\right)\left(\frac{H}{D}\right)^{0.5} \quad \text { for } \quad R e_{j}>7000
$$

From the above correlations, it is found that for $H / D$ close to one the dimensionless mixing time, $t_{m}$ $=t_{m} u_{j} d / D^{2}$, ranged from 2.6 to 9 . Since all the above tests used the dye or acid-base method, the mixing time results were based on the concentration equilibrium which may be comparable to the thermal equilibrium.

Poth and Van Hook ${ }^{5}$ conducted a mixing test by using liquid hydrogen stored in the Nuclear Propulsion Module (NPM) Mars Braking Stage. The mixing time for the tank pressure to reach its equilibrium value is about

$$
t_{m}=2.1 \frac{D^{2}}{u_{j} d}
$$

Similar experiments were conducted by Meserole et al. ${ }^{6}$ using Freon 11 at various jet diameters and liquid heights. They concluded that the mixing time determined from the pressure decay is essentially equal to that based on the equalization of temperatures throughout the bulk liquid. Also, the mixing time only varies slightly with fill levels. It seems that their data may be correlated as

$$
t_{m}=3.9 \frac{D^{2}}{u_{j} d} \quad \text { for } \quad R e_{j}>20000
$$


The reduction of tank pressure is mainly due to the vapor condensation at the interface. The mixing time definition based on the pressure equilibrium should be affected by the pressure decay rate which is controlled by the vapor condensation rate at the interface and the thermodynamic state of the vapor.

Several experiments have been conducted for the measurement of the steady state vapor condensation rate at the liquid-vapor interface in a jet-induced mixing tank. Thomas ${ }^{7}$ measured the condensation rate of steam on water surfaces mixed by a submerged turbulent jet and attempted to correlate his data based on the theoretical model proposed by Theofanous et $\mathrm{al}^{8}$. Theofanous model suggests that the condensation heat transfer coefficient be proportional to the Reynolds number to a power of 0.75 . Dominick ${ }^{9}$ investigated the effects of jet injection angle and jet flow rate on the condensation rate in a Freon 113 tank. The interface heat transfer was observed to increase as jet injection angle became more normal to the interface. Dominick ${ }^{9}$ correlated his data by using the correlation form which was developed for a turbulent jet impinging on a flat surface. In this correlation, the average heat transfer coefficient increases with increasing jet Reynolds number to a power of 0.73 . Sonin et al. ${ }^{10}$ obtained an empirical correlation for the rate at which a pure vapor condenses on the free surface of a turbulent liquid in a steam-water system, for the conditions where buoyancy effects are insignificant. The vapor was saturated and the vapor condensation was controlled by the interface turbulence at the liquid side. Their vapor condensation rate correlation is expressed as

$$
\begin{aligned}
\mathrm{St}_{\mathrm{c}} & =\frac{\mathrm{m}_{\mathrm{c}} \mathrm{h}_{\mathrm{fg}_{\mathrm{g}}}}{\mathrm{A}_{\mathrm{g}} \rho \mathrm{C}_{\mathrm{p}} \mathrm{v}_{\mathrm{s}}\left(\mathrm{T}_{\mathrm{s}}-\mathrm{T}_{\mathrm{b}}\right)} \\
& =0.0198 \mathrm{Pr}^{-0.33}(1-0.5 \mathrm{Ja})
\end{aligned}
$$

where $\mathrm{St}_{\mathrm{c}}$ is the average condensation Stanton number and $m_{c}$ is the average vapor mass condensation rate at the interface. The liquid subcooling $\left(T_{s}-T_{b}\right)$ and average turbulence intensity at the interface $\left(v_{s}\right)$ are mainly responsible for the vapor condensation rate. The average turbulent $\mathrm{rms}$ velocity at the interface, $v_{\mathrm{z}}$, is determined by ${ }^{11}$

$$
v_{s}=21.1\left(\frac{Q_{j}}{D d}\right) \exp \left(-1.2 \frac{H}{D}\right) \quad \text { for } \quad 3.1<\frac{H}{D}<4.2
$$

and by ${ }^{12}$

$$
\begin{array}{r}
v_{\mathrm{s}}=\frac{\mathrm{u}_{\mathrm{j}} \mathrm{d}}{\mathrm{D}}\left[10.04 \beta_{2}-\left(7.14 \beta_{2}-3.06 \beta_{1}\right) \frac{\mathrm{H}}{\mathrm{D}}\right] \\
\text { for } 0.5<\frac{\mathrm{H}}{\mathrm{D}}<3
\end{array}
$$

where $\beta_{1}=0.34$ and $\beta_{2}=0.24$. Lin and Hasan ${ }^{13}$ numerically solved the conservation equations with $k-\varepsilon$ turbulence model and obtained that

$v_{s}=\frac{u_{j} d}{D}\left(2.39-0.645 \frac{H}{D}\right)$ for $0.5<\frac{H}{D}<3$

Equation (11) yields $\beta_{1}=0.33$ and $\beta_{2}=0.23$ which are in good agreement with the results of Ref. 12. It is noted that Eqs. (9) to (11) were obtained for a cylindrical tank with the jet nozzle outlet located near the tank bottom. The liquid height from the tank bottom $(\mathrm{H})$ is nearly the same as jet submergence depth $\left(\mathrm{H}_{\mathrm{j}}\right)$. For most of the practical applications, they are not the same and $H_{j}$ is suggested to be used instead of $\mathrm{H}$.

This paper presents the experimental results of the pressure decay of a liquid hydrogen tank mixed by an axial turbulent jet directed normally towards the liquidvapor interface. The controlling variables are the jet volume flow rate and liquid fill level. Since the tank pressure is decreasing during the fluid mixing, the condensation rate is changing with time because of the change in jet subcooling. The steady state condensation rate correlation developed by Sonin et al. ${ }^{10}$ is modified to be expressed as a function of jet subcooling $\left(T_{8}-T_{j}\right)$. The transient condensation rate during the mixing process is then predicted by this modified steady state condsensation rate correlation using the instantaneous jet subcooling. The correlations of the mixing time, based on both the thermal equilibrium and the pressure equilibrium, are developed and are compared with other experimental data.

\section{The Experiment}

The mixing tests are performed in a nearly cylindrical dewar. The dewar is a vacuum jacketed stainless steel tank containing multilayer insulation (MLI) within the vacuum annulus. The lid is composed of a flat flange which supports a short cylindrical section with an inverted dome bottom. The space between the flange 
and the cylindrical section is evacuated and insulated with MLI to minimize heat leak through the dome from the environment. With the lid in place, the interior walls of assembled tank form a cylindrical storage volume with dome ends. The assembled tank then has an internal volume of about $0.144 \mathrm{~m}^{3}$ with an internal height of $0.711 \mathrm{~m}$ and an inside diameter of $0.559 \mathrm{~m}$. Because of the lid mounted penetrations and the coupling of the lid walls to ambient temperatures at the tank flange, the heat leak is very nonuniform. The average wall heat flux for the tank is experimentally determined and ranges from 3.15 to $\$ 1.5 \mathrm{~W} / \mathrm{m}^{2}$ for fill levels ranging from 30 to 85 percent. The Shuttle Centaur mixer is installed near the central part of the tank bottom with the jet nozzle outlet located about $0.178 \mathrm{~m}$ from the bottiom. The jet nozzle has an inner diameter of $0.0221 \mathrm{~m}$. With the mixer on, the tank fluid is withdrawn and ejected through the jet nozzle normally towards the liquid-vapor interface, resulting in axial jet-induced mixing in the tank. Figure 1(a) shows a rough sketch of the tank. It is noted that the dewar used in the present mixing test is indeed the receiver dewar of the no-vent fill tests in Ref. 14. The details of the structure, piping systems and the data acquisition system can be found in Ref. 14 .

Liquid height is measured by a capacitance level probe. An instrument tree containing silicon diodes and thermistors at varying heights is in direct contact with the tank fluid. The accuracy of the silicon diodes is about $0.6 \mathrm{~K}$ at $\mathrm{LH}_{2}$ temperatures. Six silicon diodes are located at 0.5-, 20-, 40, 50-, 60-, and 80-percent fill height to measure the fluid temperatures. Four thermistors are utilized to indicate the presence of liquid or vapor. The capacitance level probe is calibrated against the thermistors (point sensors) and is found to agree within $0.0254 \mathrm{~m}$ for liquid levels greater than 10 percent. There are two additional silicon diodes used to measure the tank dome temperatures. Figure 1(b) illustrates the temperature sensor and thermistor locations for the test tank. Pressure transducers are used to provide continuous pressure measurement throughout the system with an estimated accuracy of $\pm 1.7 \mathrm{kPa}$. A silicon diode and a flow meter are also installed in the transfer line of the mixer unit to measure the jet temperature and jet volume flow rate, respectively.

Before each test, the tank is vented to 40 to $60 \mathrm{kPa}$ at a specified liquid fill level. In order to establish the initial conditions for each test, the tank vent valve is then closed. Due to the ambient heat flux through the tank wall, the tank pressure increases and the liquid becomes thermally stratified. When the tank pressure reaches a preset level, the mixer is turned on at a specified jet volume flow rate and the test is considered to begin. The data for the liquid fill level, fluid temperatures, tank pressure, and jet flow rate are measured starting just prior to activating the mixer. During each test, the sampling rates of the measurement are varied from once every $2 \mathrm{sec}$ to once every $10 \mathrm{sec}$. The mixer is turned off when the pressure measurement does not show any pressure decrease for a specified period of time. The vent valve is then open and the test is terminated.

\section{$\underline{\text { Results and Discussion }}$}

Four series of experiments consisting of 12 tests have been conducted. Table 1 shows the experimental conditions for all the testa. The liquid fill ranged from 42 to 85 percent (by volume) and the initial liquid subcooling due to thermal stratification ranged from 4.9 to $0.2 \mathrm{~K}$. The jet flow rates varied from 0.409 to $2.43 \mathrm{~m}^{3} / \mathrm{hr}$. During each test period, the liquid fill level and the dome temperature hardly changed. Therefore, only their initial values are shown in the table.

Figures 2(a) to (d) show the tank pressure decay as a function of time for various jet volume flow rates. It is seen that the pressure decay rate is higher for the higher jet flow rate as the result of the enhanced vapor condensation at the liquid-vapor interface. Also note in Figs. 2(a) to (d), the lowest jet flow rates substantially increase the mixing time. The typical liquid temperature distributions as functions of time are shown in Figs. 3(a) and (b). The liquid temperature is completely destratified and the tank pressure reaches its equilibrium value. This equilibrium pressure is nearly the same as the saturation pressure corresponding to the uniform bulk liquid temperature of the tank. For the tests of the same series, the tank almost reaches the same equilibrium pressure. This is because their initial experimental conditions such as liquid fill, tank pressure, and fluid temperature distributions are nearly the same and thus should have the same equilibrium state when the tank is completely mixed.

The mixing characteristics for all the tests are given in Table 2. The jet Reynolds number ranges from 27900 to 160300 . A Richardson number, $\mathrm{Ri}$, is also included in Table 2 to characterize the effect of buoyancy. The definition of the Richardson number is based on the initial jet subcooling $\left(T_{s}-T_{j}\right)_{i}$, jet submergence depth $\left(H_{j}\right)$, and jet velocity $\left(u_{j}\right)$. The value of Richardson number ranges from 0.07 to 2.62 . Two mixing times are shown in the table: $\left(t_{m}\right)_{t h}$ and $\left(t_{m}\right)_{p}$. The mixing time, $\left(t_{m}\right)_{t h}$, is defined as the time required from the start of a mixing operation to the time when the liquid temperature is destratified. The mixing time, $\left(t_{m}\right)_{p}$, is defined as the time required from the start of a mixing operation to the time when the equilibrium tank pressure is achieved. Table 2 shows that, for small Ri, the dimensionless mixing time $\left(t_{m}^{*}\right)_{t h}$ is independent of the jet Reynolds number. The dimensionless mixing time $\left(t_{m}\right)_{t h}$ as a function of Richardson number is shown in Fig. 4. As shown in Fig. 4 the effect of buoyancy on the mixing 
time is negligible for $\mathrm{Ri}<0.5$. The small value of $\mathrm{Ri}$ can be obtained by increasing the jet velocity $\left(u_{j}\right)$ or decressing the gravity level $(\mathrm{g})$. Therefore, the dimensionless mixing time for the high jet flow rates in a normal-gravity condition may be applied to the low jet flow rates in a zero-gravity environment, assuming the effect of liquid-vapor interface configuration is neglected. Using the form of the correlation developed by Okita and Oyama, the mixing time data shown in Table 2 can be correlated as

$$
\begin{aligned}
\left(t_{m}^{*}\right)_{t h} & =\frac{\left(t_{m}\right)_{t h} u_{j} \mathrm{~d}}{D^{2}} \\
& = \begin{cases}4.3\left(\frac{H}{D}\right)^{0.5} & \text { Ri } \leq 0.5 \\
(3.2+2.0 \mathrm{Ri})\left(\frac{H}{D}\right)^{0.5} & \mathrm{Ri}>0.5\end{cases}
\end{aligned}
$$

Equation (12a) shows that, for $\mathrm{Ri}<0.5$, the mixing time $\left(t_{m}\right)_{t h}$ decreases linearly with increasing jet velocity for a given tank system and decreases with decreasing fill level. This finding is consistent with that of Okita and Oyama. ${ }^{3}$ However, the constant 4.3 in Eq. (12a) for our liquid hydrogen system is smaller than the constant 5.5 in Eq. (3) obtained by Okita and Oyama ${ }^{3}$ for a water system. For higher Richardson number ( $\mathrm{Ri}>0.5$ ), the mixing time is higher (as shown in Fig. 4) due to the opposing effect of the buoyancy. Equation (12b) gives the quantitative effect of buoyancy on the mixing time. It is noted that in terms of jet volume flow rate and total liquid volume, Eqs. (12a) and (12b) can be rearranged to be of the form:

$$
\begin{aligned}
& \frac{\left(t_{m}\right)_{t h} Q_{j}}{V_{1}} \\
& = \begin{cases}3.8 \frac{d D^{0.5}}{V_{1}^{0.5}} & R i \leq 0.5 \\
0.89(3.2+2.0 \mathrm{Ri}) \frac{\mathrm{dD}^{0.5}}{\mathrm{~V}_{1}^{0.5}} & \mathrm{Ri}>0.5\end{cases}
\end{aligned}
$$

Since the tank pressure is controlled by what happens in the vapor region, the values of $\left(t_{m}\right)_{t h}$ and $\left(t_{m}\right)_{p}$ may be different as shown in Table 2. If the tank is completely mixed and the bulk liquid is still subcooled, the condensation process and the pressure decrease continue. In this case, $\left(t_{m}\right)_{t h}$ is less than $\left(t_{m}\right)_{p}$. The low liquid fill data shows this phenomena. If the condensation process stops before the tank is completely mixed, then $\left(t_{m}\right)_{t h}$ is greater than $\left(t_{m}\right)_{p}$. This may happen for very high jet volume flow rates. It is obvious that the value of $\left(t_{m}\right)_{p}$ can not be correlated simply by the system parameters as those expressed in Eq. (12). The value of $\left(t_{m}\right)_{p}$ depends on the pressure decay rate which is controlled by the condensation rate at the liquidvapor interface and the thermodynamic state of the vapor region (particularly the vapor mass). This can be examined by simply looking at the equation of the pressure change rate for an isothermal vapor region. ${ }^{15}$ However, for comparison purpose, the value of $\left(t_{m}\right)_{p}$ as a function of $\mathrm{Ri}$ is plotted in Fig. 5. Similar to that for $\left(t_{m}^{*}\right)_{t h}$, buoyancy increases the value of $\left(t_{m}^{*}\right)_{p}$. With negligible buoyancy, the value of $\left(t_{m}\right)_{p}$ increases with decreasing fill level. This is because the larger vapor mess for the low fill level delays the pressure decay rate. This phenomena was also observed by Meserole et al. ${ }^{7}$ but was not discussed. Our data may be correlated by the following equation:

$$
\begin{aligned}
\left(t_{m}^{*}\right)_{p} & =\frac{\left(t_{m}\right)_{p} u_{j} d}{D^{2}} \\
& = \begin{cases}3.3 & \mathrm{Ri} \leq 0.5 \\
(2.6+2.1 \mathrm{Ri}) & \mathrm{Ri}>0.5\end{cases}
\end{aligned}
$$

For Ri less than 0.5, the constant 3.3 in Eq. (14a) is slightly less than the constant 3.9 obtained from Meserole et al.'s ${ }^{7}$ data for a Freon 11 system. It is noted that for a space system in which the gravity effect is neglected, Eqs. (12a) and (14a) may be used to predict the mixing times $\left(t_{m}\right)_{t h}$ and $\left(t_{m}\right)_{p}$, respectively.

Vapor condensation at the interface is the key mechanism to reduce the tank pressure. For a well insulated tank, the interface condensation processes are generally determined by the system parameters (such as tank geometry and size, jet nozzle size, and liquid height), fluid properties, liquid subcooling, jet flow rate, and buoyancy. Figures $B(a)$ and (b) show the jet subcooling as a function of time for high jet flow rates. With the corresponding change of tank pressure shown in Figs. 2(b) and (d), two conclusions can be drawn. First, for a given jet flow rate, pressure decay rate decreases with time due to the decrease in jet subcooling. Secondly, for a given jet subcooling, higher jet flow 
yields a greater pressure decay rate. This is because the vapor condensation rate increases with increasing jet subcooling and with the enhanced turbulence intensity near the interface (due to the increased jet flow rate).

The vapor condensatin rate correlation developed by Sonin et al. ${ }^{10}$ is expressed as

$$
\begin{aligned}
S t_{c} & =\frac{m_{c} h_{f g}}{A_{s} \rho C_{p} v_{s}\left(T_{s}-T_{b}\right)} \\
& =0.0198 \mathrm{Pr}^{-0.33}(1-0.5 \mathrm{Ja})
\end{aligned}
$$

Since this correlation is for steady state, there is a direct relationship between the interface temperature $\left(T_{s}\right)$, bulk liquid temperature $\left(T_{b}\right)$, and jet temperature $\left(T_{j}\right)$. The subcooled jet is the real driver to induce the vapor coondensation. The subcooled jet $\left(T_{j}\right)$ approaches and sweeps over the interface, and induces the vapor condensation at the interface. The jet flow absorbs the energy through this condensation process and leaves the interface at a temperature $T_{b}$. Therefore, the bulk liquid temperature $\left(T_{b}\right)$ is greater than the jet temperature $\left(T_{j}\right)$ and is less than the interface temperature $\left(T_{b}\right)$. In the mixing test, the condensation process is transient because the interface temperature keeps decreasing. It may be difficult to measure the temperature $T_{b}$ because the condensation-induced thermal layer is growing and the temperature $T_{b}$ is changing with time. Therefore, it will be helpful if the liquid subcooling $\left(T_{a}-T_{b}\right)$ in Eq. (15) can be expressed as a function of the jet subcooling. $\left(T_{\text {. }}\right.$ $-T_{j}$ ) which can be easily obtained in the experiment.

Based on the mass and energy balance, Lin and Hasan $^{16}$ have theoretically obtained the following relationship between $\left(T_{b}-T_{j}\right)$ and $\left(T_{b}-T_{j}\right)$ for an insulated system:

$$
\frac{m_{c} h_{f g}}{A_{s} \rho C_{p} u_{j}\left(T_{s}-T_{j}\right)}=\frac{\frac{T_{b}-T_{j}}{T_{s}-T_{j}}}{\left(\frac{D}{d}\right)^{2}\left(1+J_{a}\right)}
$$

For $\mathrm{Ja}<<1$, one can obtain

$$
\begin{aligned}
S t_{c} & =\frac{m_{c} h_{f g}}{A_{s} \rho C_{p} v_{s}\left(T_{B}-T_{b}\right)} \\
& =\frac{u_{j}}{v_{s}}\left(\frac{T_{b}-T_{j}}{T_{B}-T_{b}}\right)\left(\frac{d}{D}\right)^{2}
\end{aligned}
$$

Using Sonin et al.'s ${ }^{10}$ correlation, $\mathrm{St}_{\mathrm{c}}=0.0198 \mathrm{Pr}^{-0.33}$, we have

$$
T_{B}-T_{b}=\frac{T_{s}-T_{j}}{1+\left(\frac{D}{d}\right)^{2}\left(0.0198 P_{r}^{-0.33}\right)\left(\frac{v_{s}}{u_{j}}\right)}
$$

Equation (18) indicates that the diameter ratio $(D / d)$ is the key parameter controlling the difference between the liquid subcooling $\left(T_{s}-T_{b}\right)$ and jet subcooling $\left(T_{s}\right.$ - $T_{\mathbf{j}}$ ). For the system used in the present experiment, the value of $\left(T_{a}-T_{b}\right)$ is nearly half of $\left(T_{B}-T_{j}\right)$, if the value of $v_{\text {g }}$ is calculated by Eq. (11). Using Eq. (18), Sonin et al.'s $\mathrm{s}^{10}$ condensation rate correlation becomes

$$
\begin{aligned}
S t_{c} & =\frac{m_{c} h_{f_{g}}}{A_{s} \rho C_{p} v_{s}\left(T_{s}-T_{j}\right)} \\
& \times\left[1+\left(\frac{D}{d}\right)^{2}\left(0.0198 \operatorname{Pr}^{-0.33}\right)\left(\frac{v_{s}}{u_{j}}\right)\right] \\
& =0.0198 \mathrm{Pr}^{-0.33}(1-0.5 \mathrm{Ja})
\end{aligned}
$$

where the fluid properties are calculated based on the temperature $T_{b}$ which is obtained from Eq. (18). It is noted that Eq. (18) holds for a steady state condition. Assuming Sonin et al.'s ${ }^{10}$ condensation rate correlation is applicable to a transient state, the instantaneous values of $\left(T_{s}-T_{b}\right),\left(T_{s}-T_{j}\right)$, and $v_{s}$ should be used. Unfortunately, the information to predict $v_{s}$ as a function of time is not available. Theoretically, the steady state value of $v_{8}$ can be used only when the tank has been completely mixed and the required mixing time is that predicted by Eq. (12a). This steady state value of $v_{B}$ can be determined by Eqs. (9) and (11) for high $H / D$ and low $H / D$, respectively. The average turbulence intensity $\left(v_{s}\right)$ is expected to increase with time in a mixing process. If one uses the steady state value of $v_{s}$, the condensation rate is expected to be overpredicted at least in the initial time period of mixing process. This effect of transient $v_{\text {s }}$ may be decreased with increasing jet flow rate because the mixing time is shorter.

Based on the limited temperature measurements in the vapor region, curve fitting is used to estimate the vapor temperature distribution as a function of time. The typical fluid temperature distribution as a function of time is shown in Figs. $7(a)$ and (b). The vapor is superheated with the temperature difference $\left(T_{\text {dome }}-T_{8}\right)$ equal to about $65 \mathrm{~K}$. The solid line is the resulting curve-fitted temperature distributions at the time when 
the mixing process starts. The vapor mass is obtained based on the curve-fitted one-dimentional temperature distribution. Most of the vapor mass is confined in the region near the interface where the vapor temperatures are much lower. Figures $8(a)$ to (e) show the estimated vapor mass as a function of time for the high jet flow rates $(\mathrm{Ri}<0.5)$. The vapor mass predicted by using Eq. (19) with the steady state value of $v_{s}$ is also included in the figures for comparison. As expected the condensation rate is generally overpredicted. This is mainly due to the use of the steady state value of $v_{B}$ and slightly due to the vapor superheat. The comparison appears to improve as the jet flow rate increases. It is noted that the condensation rate is underpredicted at the jet flow rate of $2.43 \mathrm{~m}^{3} / \mathrm{hr}$ as shown in Fig. 8(c), which is the highest flow rate used in the experiment. This may be because at this high jet flow rate liquid surface breakup occurs and Sonin et al's ${ }^{10}$ condensation rate correlation does not apply. Therefore, the present data suggests that Sonin et al.'s 10 steady state condensation rate correlation may be used to predict the transient condensation rate in a mixing process if the instantaneous values of the jet subcooling and the average turbulence intensity at the interface are used.

\section{Conclusion}

Experiments were conducted to investigate the mixing time and transient vapor condensation rate at the liquid-vapor interface in a thermally stratified liquid hydrogen tank mixed by an axial jet. Two mixing time definitions, based on the thermal equilibrium $\left(t_{m n}\right)_{t h}$ and pressure equilibrium $\left(t_{m}\right)_{p}$, have been used. Under the conditions and parameter ranges in the present study, the following conclusions can be drawn:

1. The Richardson number (Ri) defined in the present study is an appropriate parameter to characterize the effect of buoyancy in the determination of mixing times $\left(t_{m}^{*}\right)_{t h}$ and $\left(t_{m}^{*}\right)_{p}$. If the Richardson number is less than 0.5 , the buoyancy effect is neglected. Therefore, the dimensionless mixing time for the high jet flow rates in a normal-gravity condition may be applied to the low jet flow rates in a zero-gravity environment if the effect of liquid-vapor interface configuration is neglected.

2. For $R i<0.5$, the mixing times $\left(t_{m}\right)_{t h}$ and $\left(t_{m}\right)_{p}$ can be predicted by Eqs. (12a) and (14a), respectively. These equations may also be applied to a space syatem in which the gravity effect is negligible. Buoyancy delays the mixing process. Equations (12b) and (14b) give the predictions of $\left(t_{m}\right)_{t h}$ and $\left(t_{m}\right)_{p}$, respectively, for $R i$ $>0.5$ based on the system used the the present study.

3. For a steady state condensation process with negligible buoyancy, the liquid subcooling $\left(T_{s}-T_{b}\right)$ can be expressed by Eq. (18) as a function of the jet subcooling $\left(T_{8}-T_{j}\right)$ and the average turbulence intensity $\left(v_{8}\right)$ at the interface.

4. The steady state condensation rate correlation of Eq. (19) may be used to predict the transient condensation rate in a mixing process if the instantaneous values of jet subcooling and average turbulence intensity at the interface are employed. However, if the liquid surface breakup occurs due to high jet flow rate, Eq. (19) may underpredict the vapor condensation rate.

\section{References}

1. Fossett, H., and Prosser, L.E., "The Application of Free Jets to the Mixing of Fluids in Bulk," Proceedings of the Institute of Mechanical Engineers, vol. 160, no. 2, pp. 224-232, 1949.

2. Fox, E.A., and Gex, V.E., "Single-Phase Blending of Liquids," J. AIChE. vol. 2, no. 4, pp. 539-544, 1956.

3. Okita, N., and Oyama, Y., "Mixing Characteristics in Jet Mixing," Chem. Eng. Japan, vol. 27, no. 4, pp. 252-259, 1963.

4. Wollen, M.A., "Evaluation of Jet Induced Mixing for Centaur $\mathrm{LH}_{2}$ Tank," NASA TM-696083-933, 1983.

5. Poth, L.J., and Van Hook, J.R., "Control of Thermodynamic State of Space-Stored Cryogens by Jet Mixing," J. Spacecraft, Vol. 9, No. 5, pp. 392-336, 1972.

6. Meserole, J.S., Jones, O.S., Brennan, S.M., and Fortini, A., "Mixing-Induced Ullage Condensation and Fluid Destratification," AIA A Paper 87-2018, 1987.

7. Thomas, R.M., "Condensation of Steam on Water in Turbulent Motion," Int. J. Multiphase Flow, vol. 5, no. 1, pp. 1-15, 1979.

8. Theofanous, T.G., Houze, R.N., and Brumfield, L.K., "Turbulent Mass Transfer at Free, Gas-Liquid Interfaces, with Applications to Open-Channel, Bubble, and Jet Flows," Int. J. Heat Mass Transfer, Vol. 19, pp. 613-624, 1976.

9. Dominick, S.M., "Mixing Induced Condensation Inside Propellant Tanks," AIAA Paper 84-0514, 1984. 
10. Sonin, A.A., Shimko, M.A., and Chun, J.H., "Vapor Condensation onto a Turbulent Liquid-I. The Steady State Condensation Rate as a Function of Liquid-Side Turbulence," Int. J. Heat Mass Trans., Vol. 29, No. 9, pp. 1319-1332, 1986.

11. Brown, J.S., Khoo, B.C., and Sonin, A.A., "Rate Correlation for Condensation of Pure Vapor on Turbulent, Subcooled Liquid," Int. J. Heat Mass Trans., Vol. 33, No. 9, 1990.

12. Brown, J.S., Helmick, M.R., and Sonin, A.A., "Vapor Condensation at a Turbulent Liquid Surface in Systems with Possible Space-Based Applications," AIAA Paper 89-2846, July 1989.

13. Lin, C.S. and Hasan, M.M., "Effect of Liquid Surface Turbulent Motion on the Vapor Condensation in a Mixing Tank," Proceedings of the 4th International Symposium on Transport Phenomena in Heat and Mass Transfer, Sidney, Australia, July 14-19, 1991, Transport Phenomena in Heat and Mass Transfer, J.A. Reizes, ed., pp. 1526-1537, 1992.

14. Moran, M.E., Nyland, T.W., and Papell, S.S., "Liquid Transfer Cryogenic Test Facility-Initial Hydrogen and Nitrogen No-Vent Fill Data," NASA TM-102572, 1990.

15. Lin, C.S., and Hasan, M.M, "Self-Pressurization of a Spherical Liquid Hydrogen Storage Tank in a Microgravity Environment," AIAA Paper 92-0363, 1992.

16. Lin, C.S., and Hasan, M.M, "Vapor Condensation on Liquid Surface Due to Laminar Jet-Induced Mixing," J. Thermophysics and Heat Transfer, vol. 5, no. 4, pp. 607-612, 1991.

TABLE 1.-THE INITIAL AND FINAL CONDITIONS OF THE TEST

\begin{tabular}{|c|c|c|c|c|c|c|c|}
\hline \multirow[t]{2}{*}{$\begin{array}{l}\text { Test } \\
\text { series }\end{array}$} & \multicolumn{2}{|c|}{$\begin{array}{c}\text { Liquid fill, } \\
\text { percent }\end{array}$} & \multicolumn{2}{|c|}{ Initial conditions } & \multirow{2}{*}{$\begin{array}{c}\text { Final } \\
\text { conditions, } \\
\text { P, } \\
\text { kPa }\end{array}$} & \multirow{2}{*}{$\begin{array}{c}\text { Dome } \\
\text { temperature, } \\
\underset{\mathbf{K}}{\mathbf{T}_{\text {domel }}}\end{array}$} & \multirow{2}{*}{$\begin{array}{c}\text { Jet flow } \\
\text { rate, } \\
\mathrm{Q}_{\mathrm{j}} \\
\mathrm{m}^{3} \mathrm{hrr}_{\mathrm{hr}}\end{array}$} \\
\hline & by height & by volume & $\begin{array}{c}\mathbf{P} \\
\mathbf{k P a}\end{array}$ & $T_{K}-T_{j}$ & & & \\
\hline Al & 76 & 85 & 235.1 & 6.1 & 43.4 & 63.9 & 0.568 \\
\hline A2 & 74 & 83 & 202.7 & 6.1 & 38.6 & 67.2 & .772 \\
\hline A3 & 73 & 81 & 238.5 & 6.2 & 40.0 & 75.6 & .681 \\
\hline B1 & 72 & 80 & 199.2 & 5.5 & 42.0 & 77.8 & .409 \\
\hline B2 & 71 & 78 & 200.6 & 5.4 & 36.5 & 82.2 & 1.045 \\
\hline $\mathbf{B 3}$ & 70 & 77 & 187.5 & 5.2 & 36.5 & 85.0 & 1.635 \\
\hline B4 & 68 & 75 & 188.2 & 5.2 & 37.9 & 88.9 & 2.430 \\
\hline C1 & 42 & 44 & 184.0 & 4.9 & 57.9 & 129.4 & .409 \\
\hline $\mathrm{C2}$ & 41 & 42 & 188.9 & 5.0 & 57.9 & 137.2 & .681 \\
\hline D1 & 66 & 73 & 218.5 & 6.2 & 46.9 & 91.1 & .454 \\
\hline D2 & 64 & 71 & 208.2 & 5.9 & 41.4 & 96.1 & 1.158 \\
\hline D3 & 63 & 70 & 197.8 & 5.7 & 42.0 & 97.2 & 1.863 \\
\hline
\end{tabular}

TABLE 2.-THE MIXING CHARACTERISTICS OF THE TEST

\begin{tabular}{|c|c|c|c|c|c|c|c|c|}
\hline $\begin{array}{l}\text { Test } \\
\text { series }\end{array}$ & $\begin{array}{c}Q_{j} \\
m^{3} / h r\end{array}$ & $\mathbf{R e}_{\mathbf{j}}$ & $\mathbf{R i}$ & $H / D$ & $\begin{array}{c}\left(t_{m}\right)_{t h} \\
\min \end{array}$ & $\begin{array}{c}\left(t_{m}\right)_{p^{\prime}} \\
\min \end{array}$ & $\frac{\left(t_{m}^{*}\right)_{1 h}}{(H / D)^{0.5}}$ & $\left(t_{m}^{*}\right)_{p}$ \\
\hline A1 & 0.568 & 38,600 & i.68 & 0.968 & 3.73 & 3.54 & 6.62 & 6.18 \\
\hline A2 & .772 & 53,200 & .77 & .943 & 2.06 & 1.60 & 5.04 & 3.80 \\
\hline A3 & .681 & 47,600 & 1.09 & .928 & 2.37 & 2.27 & 5.15 & 4.75 \\
\hline B1 & .409 & 27,900 & 2.62 & .916 & 6.60 & 6.77 & 8.67 & 8.52 \\
\hline B2 & 1.045 & 70,900 & .40 & .903 & 1.33 & 1.03 & 4.50 & 3.31 \\
\hline B3 & 1.635 & 111,500 & .15 & .877 & .80 & .60 & 4.30 & 3.02 \\
\hline $\mathbf{B 4}$ & 2.430 & 166,300 & .07 & .852 & .55 & .40 & 4.45 & 2.99 \\
\hline C1 & .409 & 28,400 & .88 & .526 & 2.80 & 4.13 & 4.86 & 5.20 \\
\hline $\mathrm{C2}$ & .681 & 46,900 & .31 & .513 & 1.37 & 1.80 & 4.01 & 3.77 \\
\hline D1 & .454 & 29,900 & 2.09 & .826 & 4.60 & 4.47 & 7.07 & 6.24 \\
\hline D2 & 1.158 & 77,200 & .30 & .801 & 1.03 & .97 & 4.10 & 3.45 \\
\hline D3 & 1.863 & 124,500 & .11 & .789 & .66 & .56 & 4.26 & 3.21 \\
\hline
\end{tabular}




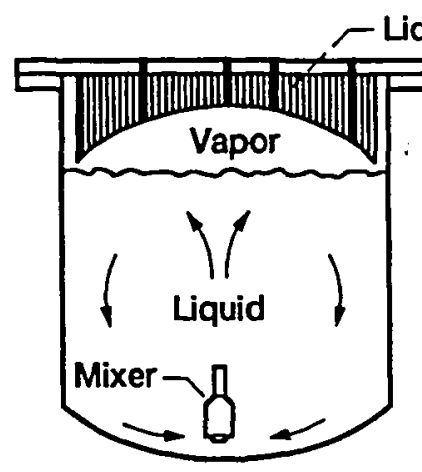

(a)
- Silicon Diode

- Thermister

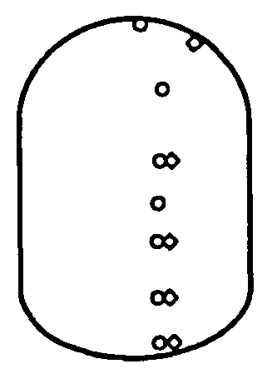

(b)

Figure 1. The sketch for the test tank and the locations of temperature sensors and thermisters in the tank. 


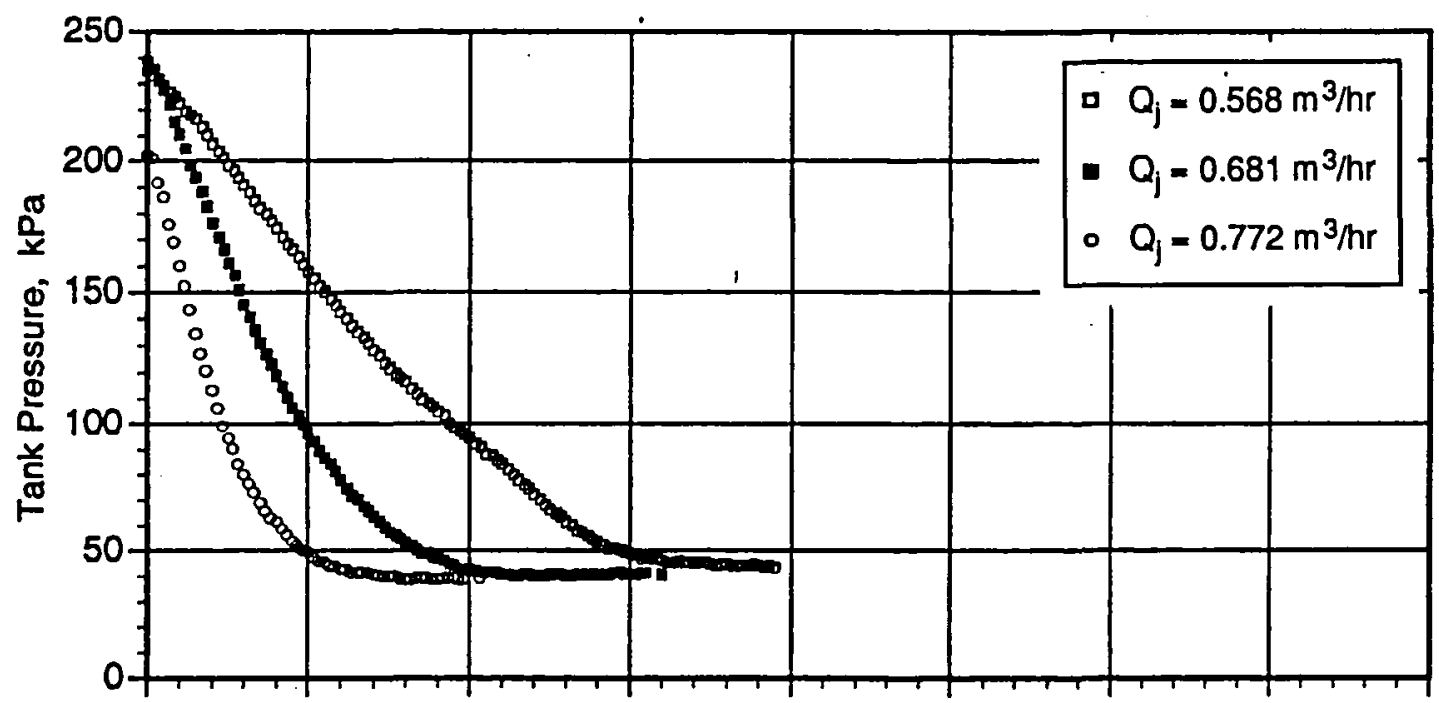

(a) Test serles A.

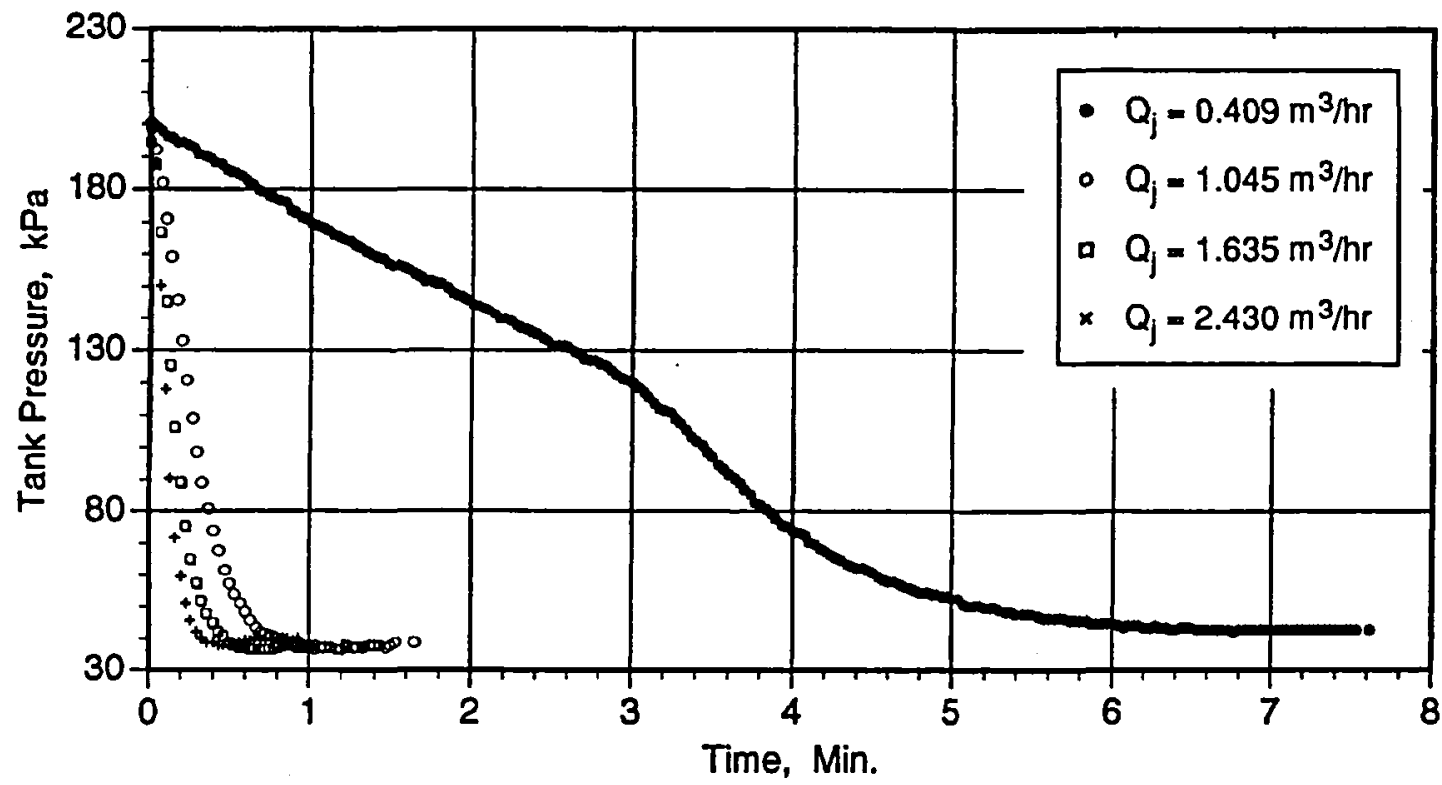

(b) Test serles B.

Flgure 2.-The change of tank pressure as a function of time. 


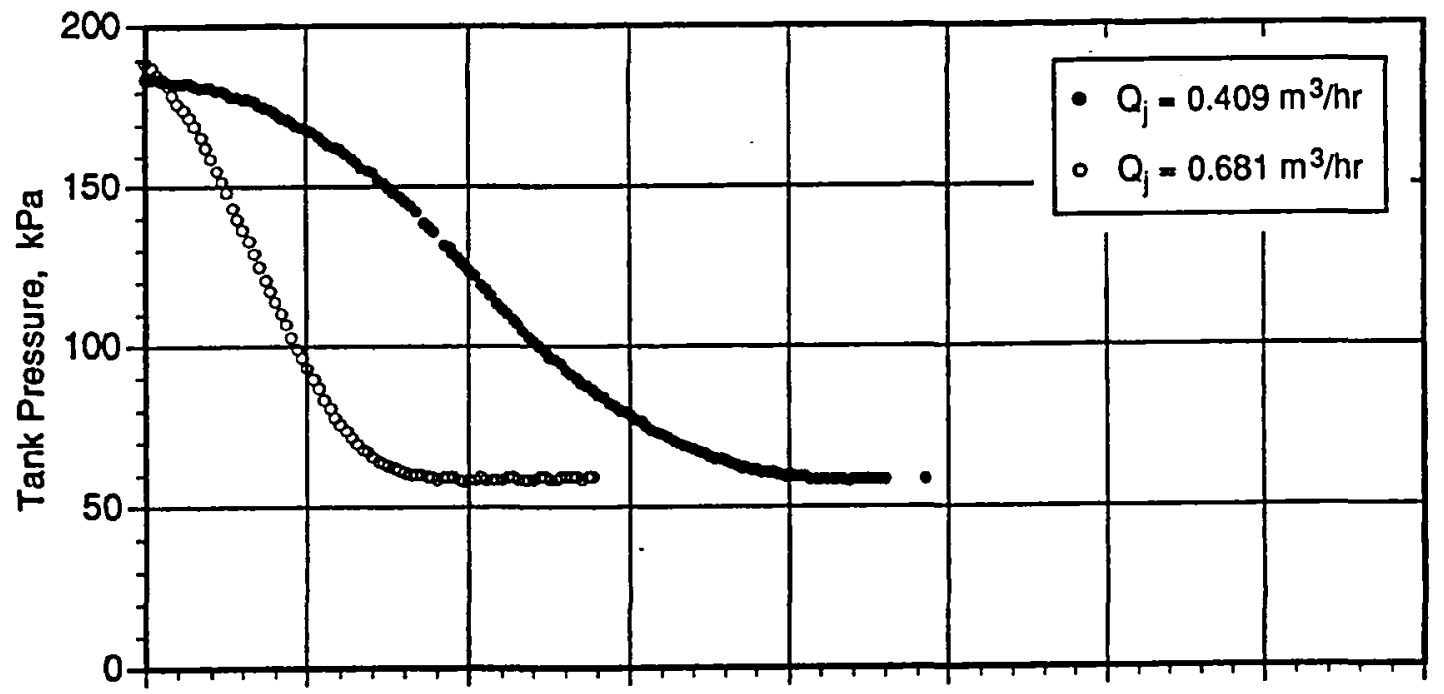

(c) Test series $\mathbf{C}$.

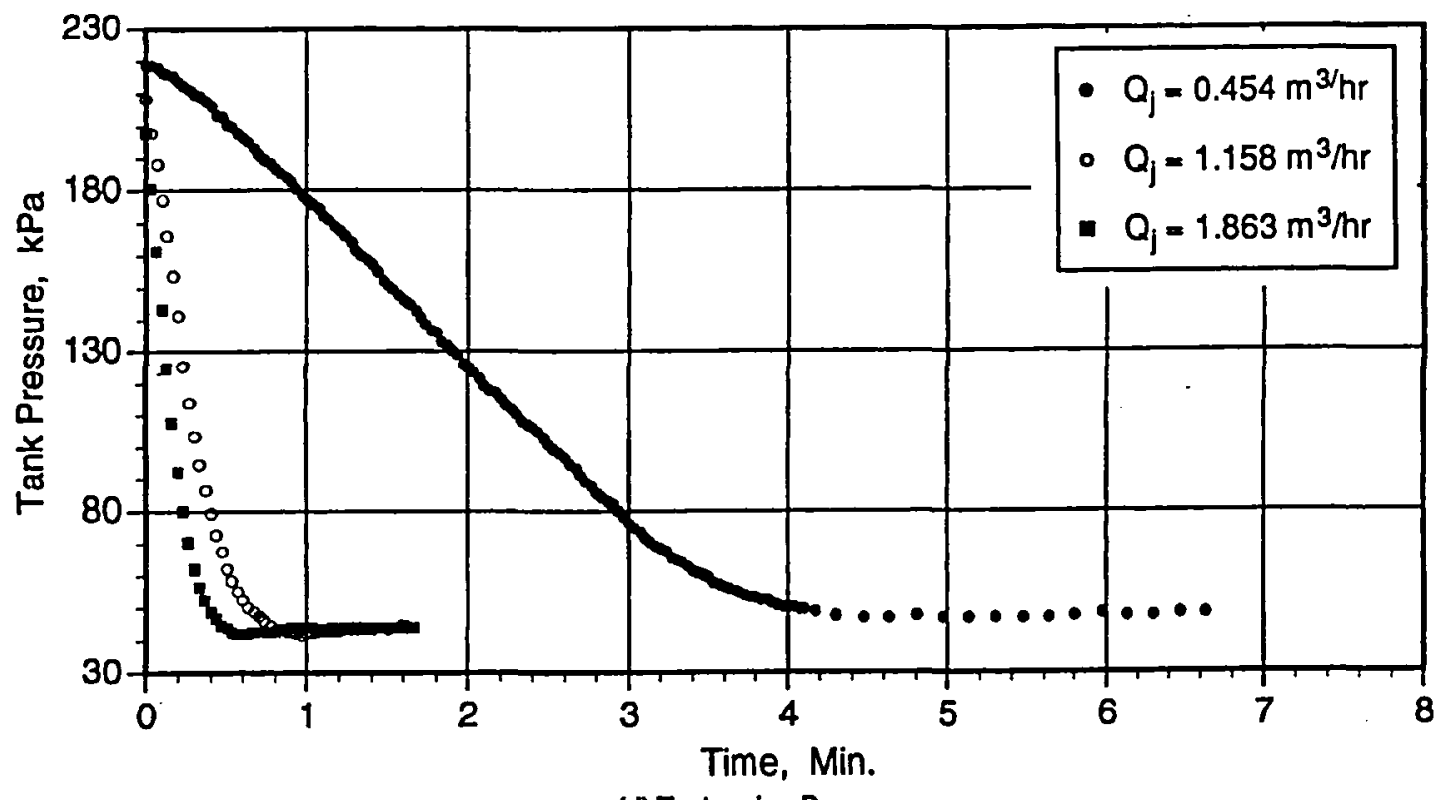

(d) Test series $D$.

Figure 2.-Concluded. 


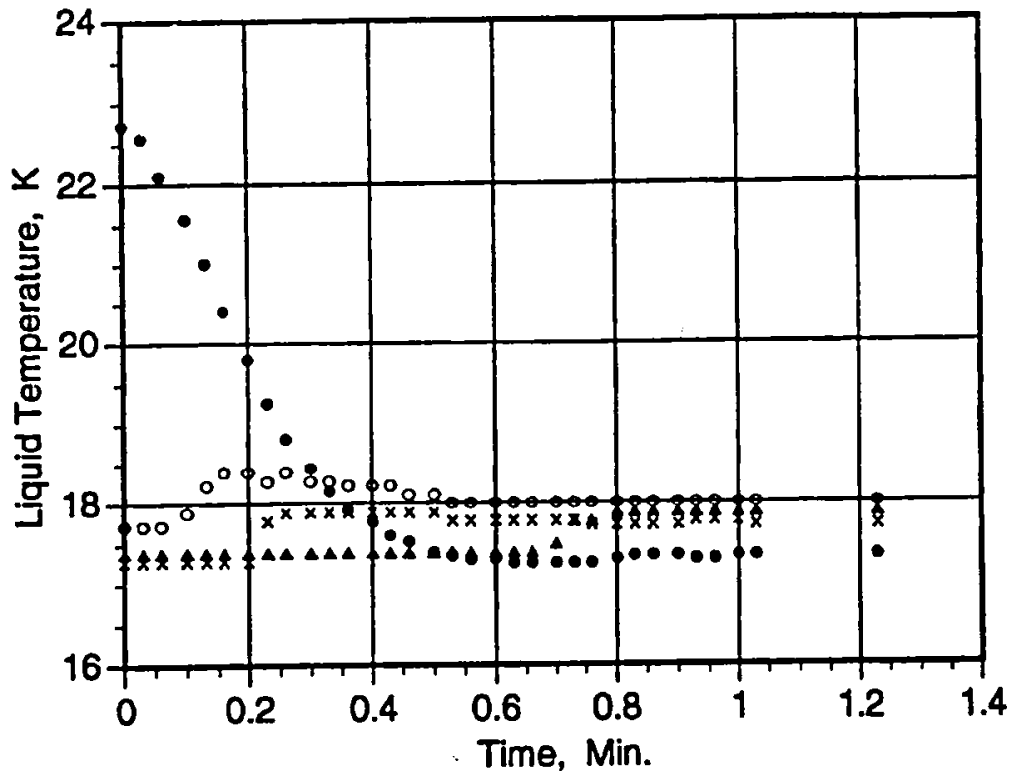

- $70 \%, \mathrm{~T}_{\mathrm{s}}$

- $60 \%$ tree sd

$\times 40 \%$ tree sd

- $0.5 \%$ tree sd

(a) Test series $B_{1} Q_{1}=1.635 \mathrm{~m}^{3} / \mathrm{hr}$.

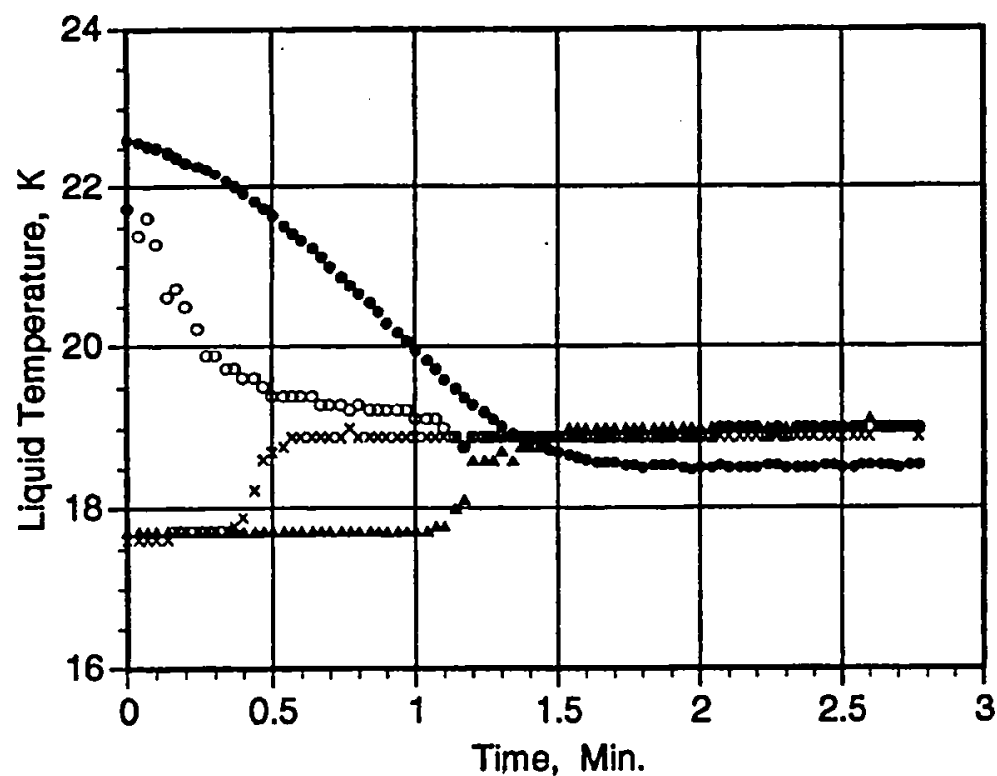

- $41 \%, T_{s}$

- $40 \%$ tree sd

$\times 20 \%$ tree sd

- $0.5 \%$ tree sd

(b) Test serles $C, Q_{1}=0.681 \mathrm{~m}^{3} / \mathrm{hr}$.

Flgure 3.-The change of llquid temperature as a function of time. 


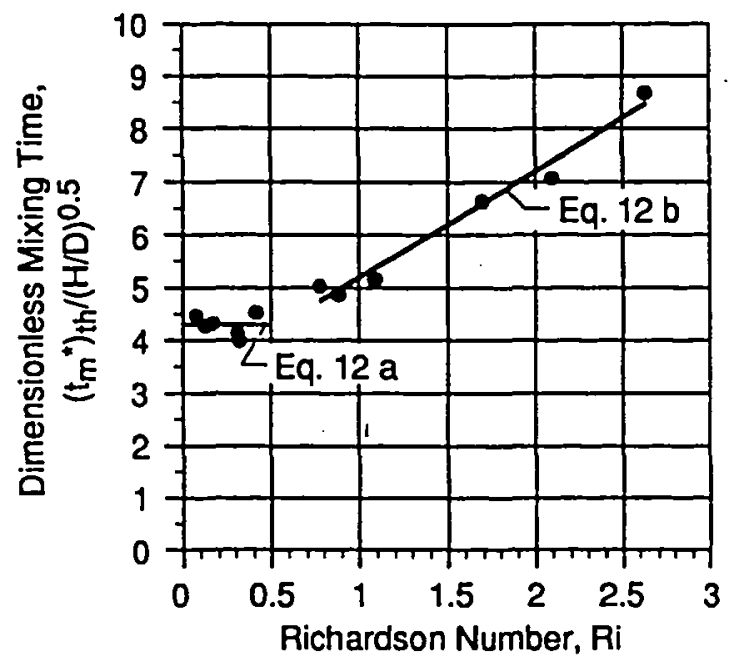

Flgure 4. - The dimensionless mixing time (based on the thermal equilibrium) as a function of Richardson number.

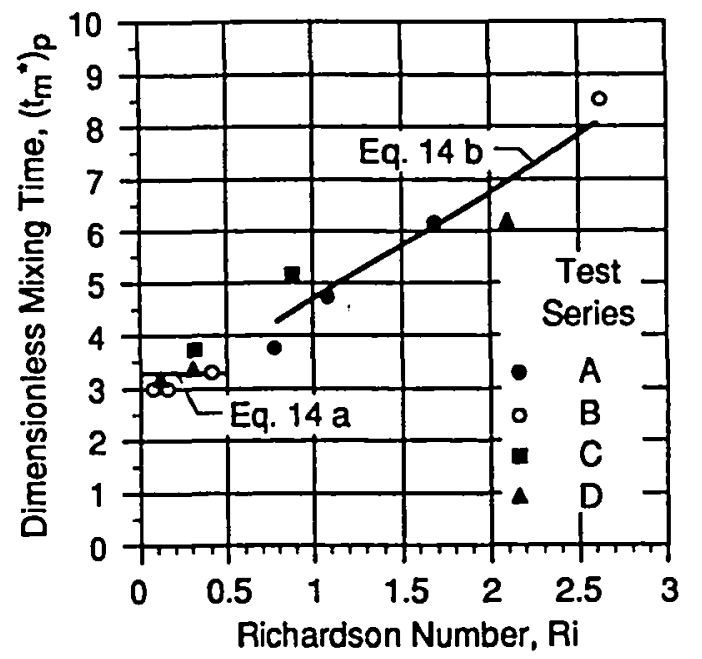

Figure 5.-The dimensionless mixing time (based on the pressure equinibrium) as a function of Richardson number. 


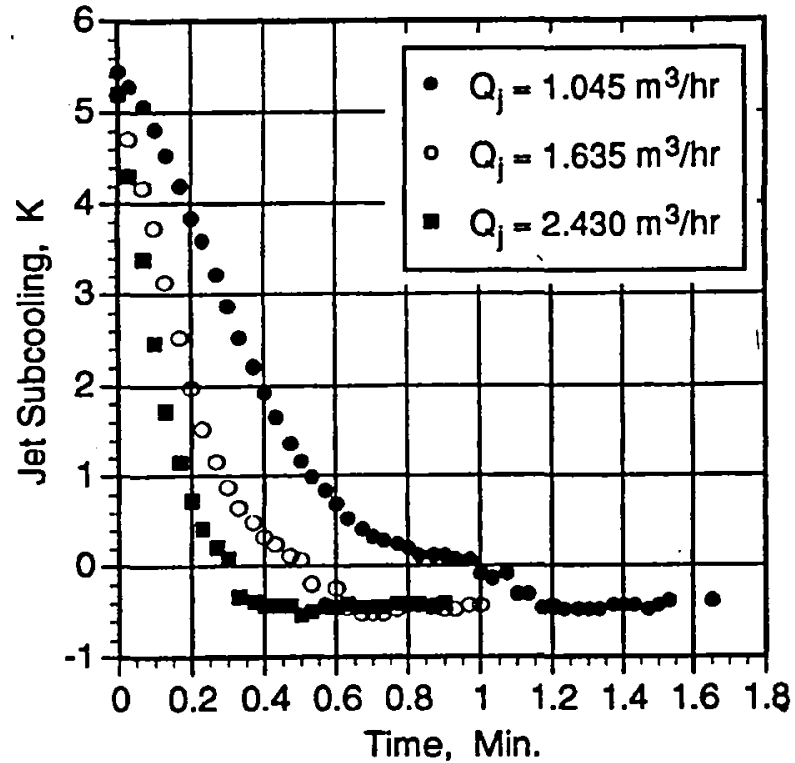

(a) Test series $B$.

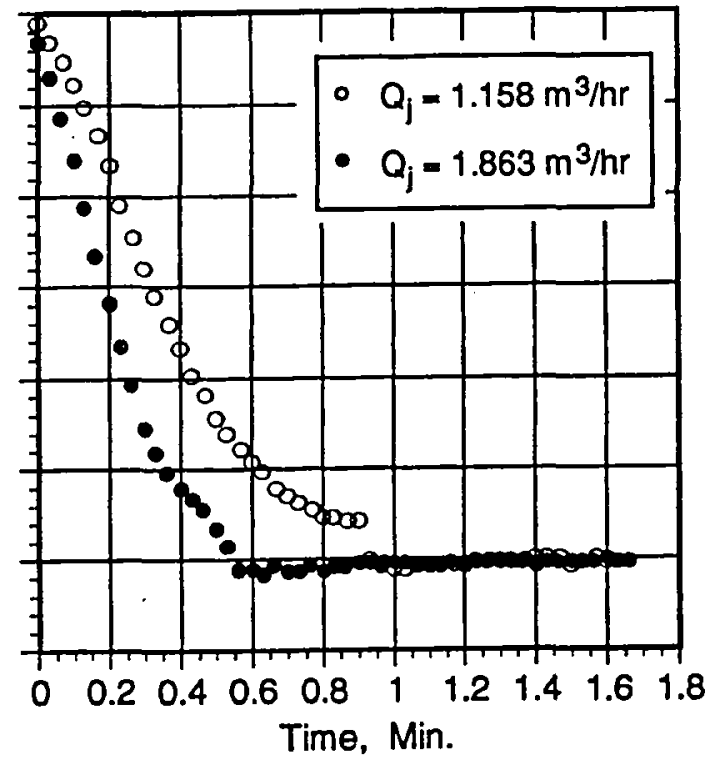

(b) Test series D.

Figure 6.-The change of the jet subcooling as a function of time. 


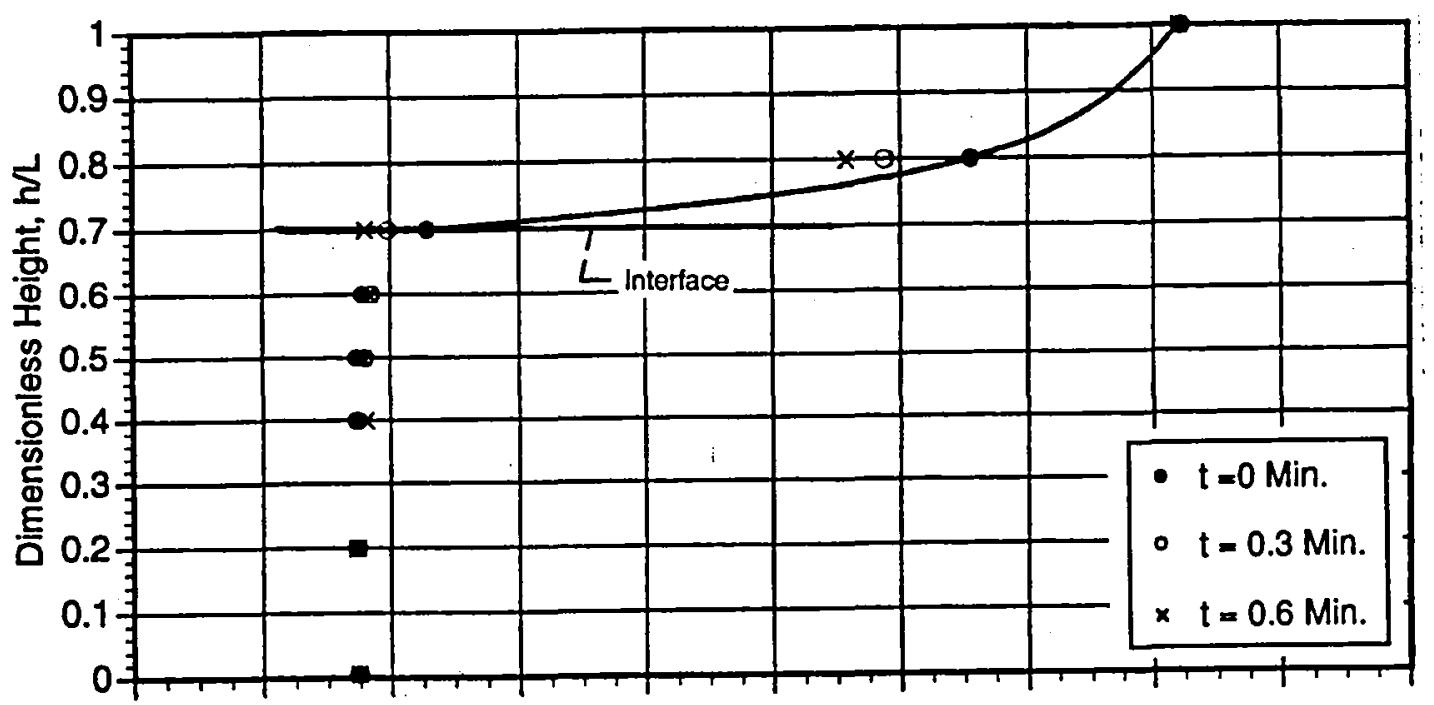

(a) Test series $B, Q_{1}=1.045 \mathrm{~m}^{3} / \mathrm{hr}$.

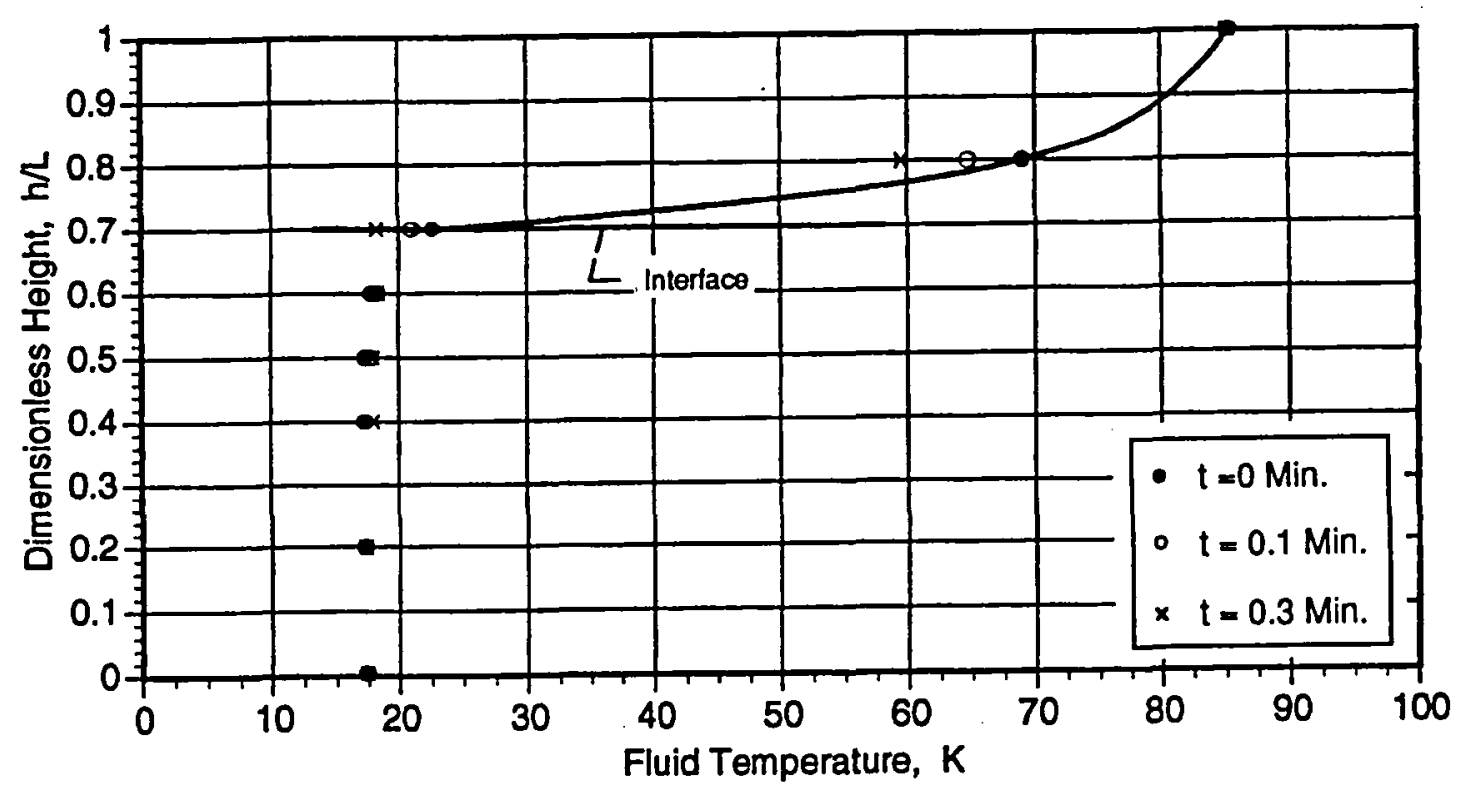

(b) Test serles $B, Q_{1}=1.635 \mathrm{~m}^{3} / \mathrm{hr}$.

Figure 7.-The fluid temperature distribution as a function of helght. 


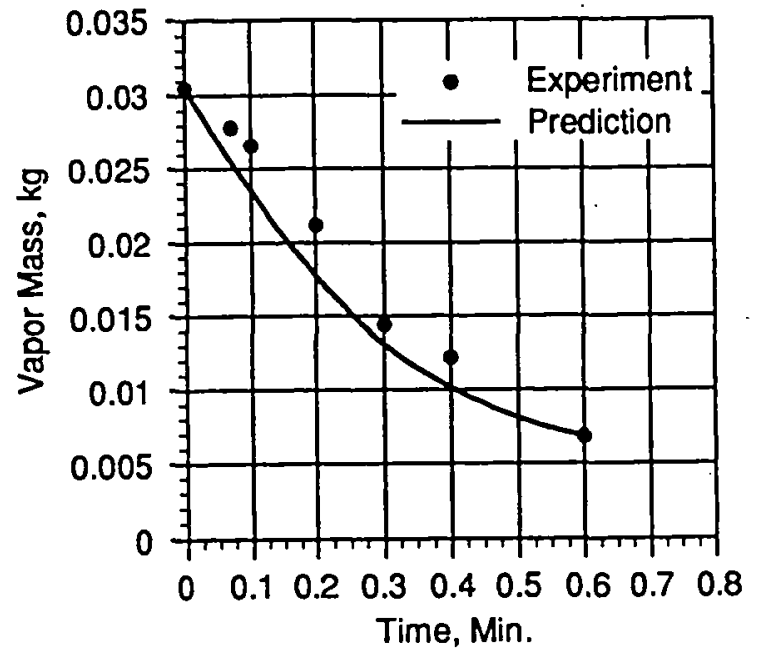

(a) Test series $B, Q_{j}=1.045 \mathrm{~m}^{3} / \mathrm{hr}$.

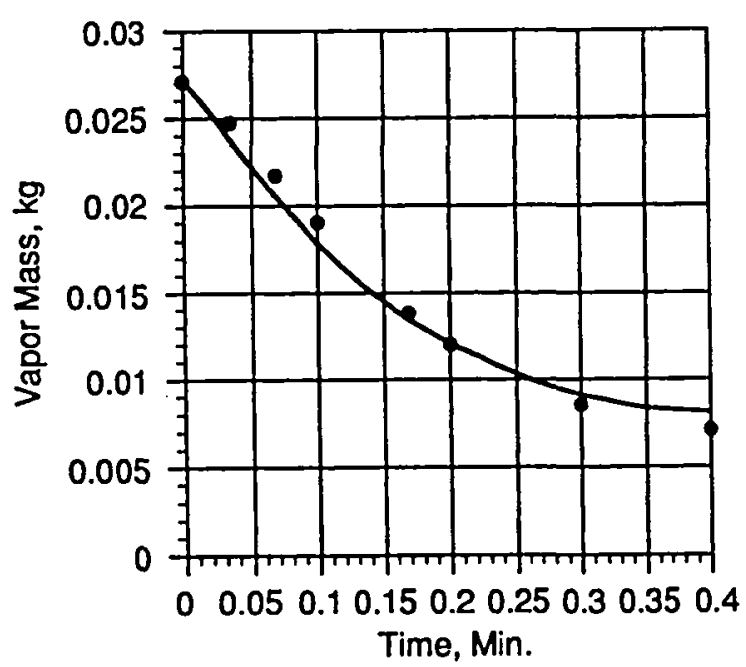

(b) Test series $B, Q_{1}=1.635 \mathrm{~m}^{3} / \mathrm{hr}$.

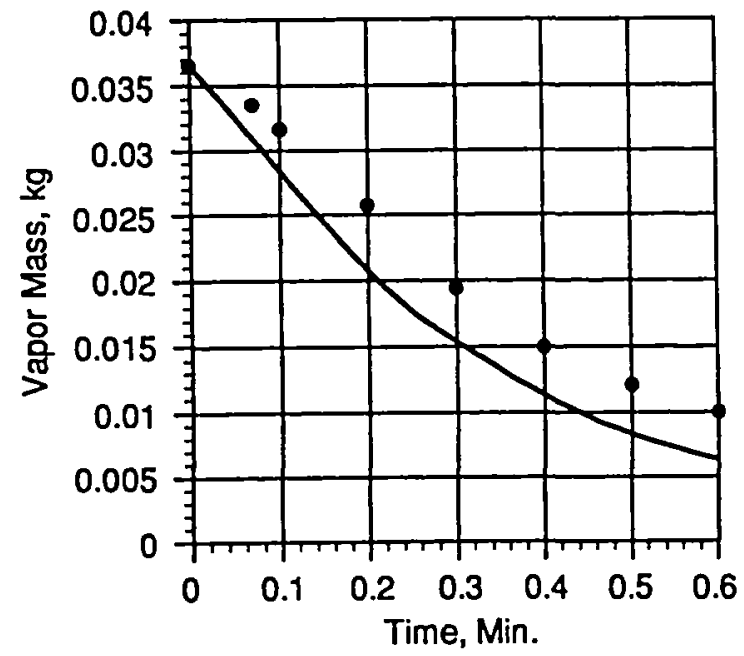

(d) Test series $D, Q_{\mathrm{J}}=1.158 \mathrm{~m}^{3} / \mathrm{hr}$.

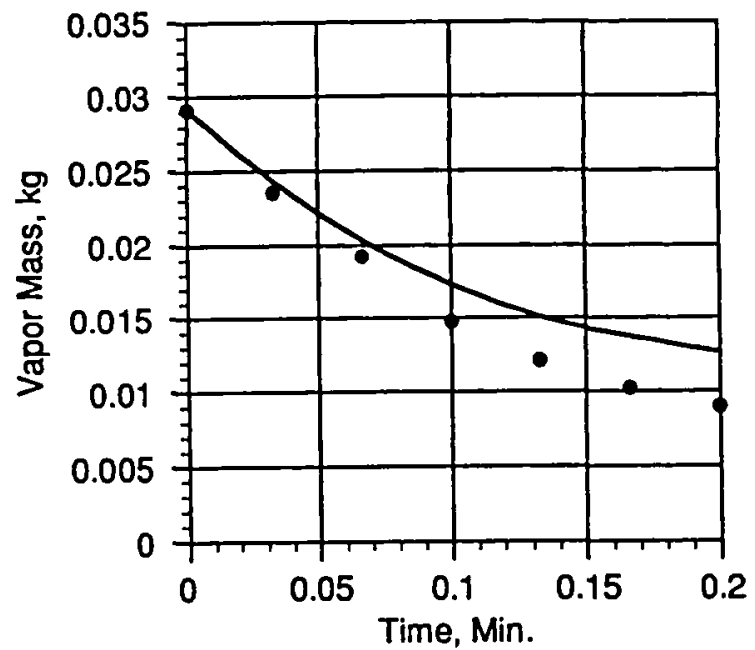

(c) Test series $B, O_{j}=2.430 \mathrm{~m}^{3} / \mathrm{hr}$.

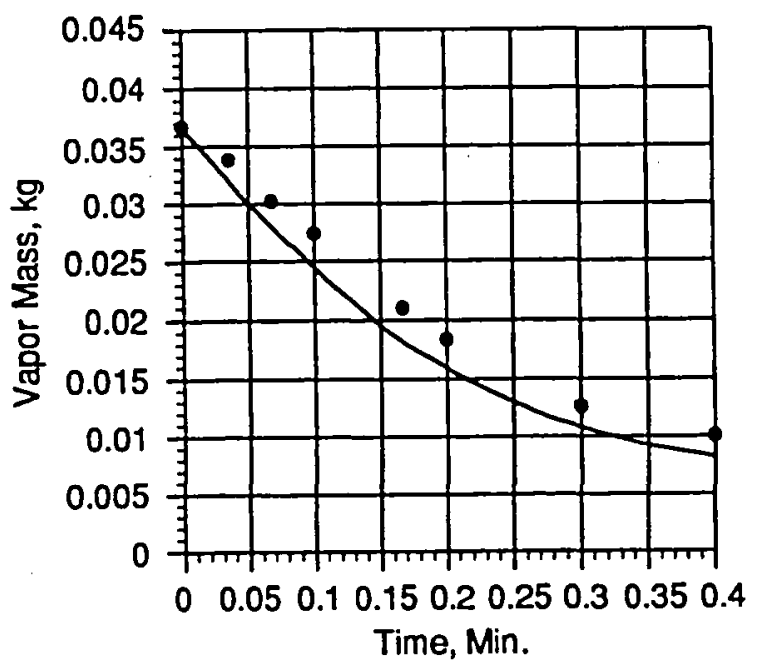

(e) Test series $D, Q_{j}=1.863 \mathrm{~m}^{3} / \mathrm{hr}$.

Figure 8. - The change of vapor mass as a function of time and its comparison with the prediction based on the condensation rate correlation equation. 

Public reporting burden for this collection of information is estimaled to, average 1 hour per response, including the time for reviewing instructions, searching existing data sources. gathering and maintaining the data needed, and completing and reviewing the collection of information. Send comments regarding this burden estimate or any other aspect of this collection of information, including suggestions for recucing this burden, to Washington Headquarters Services, Directorate for Information Operations and Reports. 1215 Jefferson Davis Highway, Suite 1204, Arlington, VA 22202-4302, and to the Office of Management and Budget, Paperwork Peduction Project (0704-0188), Washington, DC 20503.

\begin{tabular}{|l|c|c|}
\hline 1. AGENCY USE ONLY (Laave blank) & $\begin{array}{c}\text { 2. REPORT DATE } \\
\text { June } 1993\end{array}$ & $\begin{array}{r}\text { 3. REPORT TYPE AND DATES COVERED } \\
\text { Technical Memorandum }\end{array}$
\end{tabular}

\section{TITLE AND SUBTITLE}

5. FUNDING NUMBERS

Mixing and Transient Interface Condensation of a Liquid Hydrogen Tank

6. AUTHOR(S)

WU-506-42-73

C.S. Lin, M.M. Hasan, and T.W. Nyland

\section{PERFORMING ORGANEATION NAME(S) AND ADDRESS(ES)}

National Aeronautics and Space Administration

Lewis Research Center

Cleveland, Ohio 44135-3191
8. PERForming organization REPOAT NUMBER

E-7910

\section{SPONSORING/MONITORING AGENCY NAME(S) AND ADDRESS(ES)}

National Aeronautics and Space Administration

Washington, D.C. 20546-0001
10. SPONSORING/MONTORING AGENCY REPORT NUMBER

NASA TM-106201

AlAA-93-1968

11. SUPPLEMENTARY NOTES

Prepared for the 29th Joint Propulsion Conference and Exhibit cosponsored by the AIAA, SAE, ASME, and ASEE, Monterey, California, June 28-30, 1993. C.S. Lin, Analex Corporation, 3001 Aerospace Parkway, Brook Park, Ohio 44142; and M.M. Hasan and T.W. Nyland, NASA Lewis Research Center. Responsible person, C.S. Lin, (216) 433-0138.

12a. DISTRIBUTION/AVAILABILITY STATEMENT

12b. DISTAIBUTION CODE

Unclassified - Unlimited

Subject Category 34

13. ABSTRACT (Meximum 200 words)

Experiments have been conducted to investigate the effect of axial jet-induced mixing on the pressure reduction of a thermally stratified liquid hydrogen tank. The tank was nearly cylindrical, having a volume of about $0.144 \mathrm{~m}^{3}$ with $0.559 \mathrm{~m}$ in diameter and $0.711 \mathrm{~m}$ long. A mixer/pump unit, which had a jet nozzle outlet of $0.0221 \mathrm{~m}$ in diameter was located $0.178 \mathrm{~m}$ from the tank bottom and was installed inside the tank to generate the axial jet mixing and tank fluid circulation. The liquid fill and jet flow rate ranged from 42 to 85 percent (by volume) and 0.409 to $2.43 \mathrm{~m}^{3} / \mathrm{hr}$, respectively. Mixing tests began with the tank pressure ranging from 187.5 to $238.5 \mathrm{kPa}$ at which the thermal stratification results in 4.9 to $6.2^{\circ} \mathrm{K}$ liquid subcooling. The mixing time and transient vapor condensation rate at the liquid-vapor interface are determined. Two mixing time correlations, based on the thermal equilibrium and pressure equilibrium, are developed. Both mixing time correlations are expressed as functions of system and buoyancy parameters and compared well with other experimental data. The steady state condensation rate correlation of Sonin et al. based on steam-water data is modified and expressed as a function of jet subcooling. The limited liquid hydrogen data of the present study shows that the modified steady state condensation rate correlation may be used to predict the transient condensation rate in a mixing process if the instantaneous values of jet subcooling and turbulence intensity at the interface are employed.

\begin{tabular}{|l|l|}
\hline 14. SUBJECT TERMS \\
Liquid hydrogen, Jet-induced mixing; Mixing time; Liquid- \\
Vapor condensation \\
\hline $\begin{array}{l}\text { 17. SECURITY CLASSIFICATION } \\
\text { OF REPORT } \\
\text { Unclassified }\end{array}$ & $\begin{array}{c}\text { 18. SECURTY CLASSIFICATION } \\
\text { OF THIS PAGE } \\
\text { Unclassified }\end{array}$ \\
\hline
\end{tabular}

19. SECURITY CLASSIFICATION
OF ABSTRACT
Unclassified
Unclassified 
National Aeronautics and Space Administration

Lewis Research Conter

Cleveland, Ohio $\$ 4135$

Oriveled Duanines

Penarty tor Privent bee 8000
FOUATH CLASS MAIL

\section{ADDRESS COARECTION REOUESTED}

